\title{
Vulnerability to drought and food price shocks: Evidence from Ethiopia
}

\author{
Ruth Vargas Hill \\ The World Bank \\ Catherine Porter \\ Heriot-Watt University*
}

December 16, 2016

Keywords: Vulnerability, Poverty, Drought, Inflation, Ethiopia.

JEL Codes: I31, I32, I38

\footnotetext{
*Many thanks to Christopher Gaukler and Radhika Goyal for excellent research assistance, in particular for their dedication and patience in accessing and compiling the many datasets used in this study. Thanks to Jose Cuesta, Tassew Woldehanna, Matthew Hobson, Camilla Holmemo, participants at CSAE conference Oxford 2015 and anonymous reviewers for comments on earlier drafts. Comments welcome to catherine.porter@hw.ac.uk
} 


\section{Introduction}

Households in developing countries face significant uncertainty about their future consumption. There are many sources of this uncertainty, for example job insecurity, ill health that affects the productive labor and income of a household, death of family members, drought that reduces crop yields and incomes and, more recently, price shocks that make purchasing basic food supplies more difficult for those with few resources.

The importance of risk for decision making and the consequences of realized shocks have become an ever-more important focus for policymakers as evidenced by the World Development Reports of 2001 and 2014 (World Bank, 2014). The increasing availability of data on shocks, particularly those that are experienced by entire communities at once (such as weather shocks and price shocks), allow for better estimates of the welfare impact of shocks. It also allows for new forward-looking quantitative research on the intersection of poverty and risk.

It is to this literature that this paper aims to add, by applying and extending lessons from both theoretical and empirical work on shocks and vulnerability to a newly compiled dataset that is nationally representative, and used to calculate official estimates of poverty. ${ }^{1}$ The methodology we use is of general interest, as it combines several new ideas for estimating the impact of rainfall and price shocks on welfare using cross-sectional data, and combining these estimates with long-run data on rainfall and prices to generate estimates of household vulnerability. Although the availability of panel data surveys is improving for developing countries, they are not yet widespread, often are small in size, and not nationally representative. Vulnerability estimates have either relied on self-reported shocks and short, unrepresentative panel surveys (Calvo and Dercon, 2013; Klasen et al., 2015), or on the cross-sectional distribution of consumption (Chaudhuri, 2003)), neither of which are completely satisfactory. We show that measures of vulnerability that properly take covariate shocks into account can result in a very different understanding of welfare differences across groups than poverty measures at one point in time. This highlights the importance of considering such measures of vulnerability when designing poverty-targeted programs in many African countries where poverty is infrequently measured and covariate shocks are important.

Economists have recently incorporated rainfall data as an exogenous source of shocks in various empirical models to estimate ex-post impacts of weather (Dell et al., 2014). The impact of weather shocks on consumption outcomes for households has been analyzed in this way for a small sample of villages in rural Ethiopia by amongst others Dercon and Krishnan (2000); Dercon (2004); Porter (2012), and similarly food price shocks in urban areas have been analyzed using a household panel by Alem and Söderbom (2012). In this paper we quantify the welfare impact of drought and price inflation at a national level in Ethiopia. We use community (woreda) level information on rainfall-induced crop-losses as the objective measure of rainfall shocks and control for the probability of drought in a given community using the historic distribution of drought. Conditional on the probability of drought, the timing of the shock is considered to be exogenous.

\footnotetext{
${ }^{1}$ The dataset we use has full coverage of all but the pastoral areas of Afar and Somaliland.
} 
Other unobserved geographic characteristics are controlled for by the inclusion of district (zone) fixed effects. ${ }^{2}$

In addition, to date, no study has used the historical distribution of covariate shocks to estimate the distribution of future consumption and poverty. Existing studies rely instead on cross-sectional variation in shocks which does not accurately take into account the welfare volatility that arises from events that vary more across time than space. We combine time-series information on rainfall-induced crop losses at the community level with the estimated impact of rainfall losses on consumption to predict future consumption (in combination with similar estimates of the impact of price shocks and idiosyncratic shocks). Using the estimated probability distribution of future consumption we calculate national estimates of vulnerability to poverty and also illustrate differences in vulnerability to poverty between groups such as urban and rural, or by geographic status (though with caveats around the meaning of 'vulnerability' discussed below).

There are four reasons why we may consider Ethiopia a pertinent case study for a focus on vulnerability. First, the Ethiopian economy is still largely comprised of rainfed agriculture in an agroclimatic environment that has been no stranger to extreme drought in recent decades. Vulnerability to weather risk has historically been very high among agricultural subsistence farmers, which describes the majority of Ethiopian rural households. Almost half of rural households in Ethiopia were affected by drought in a five year period from 1999 to 2004 (Dercon et al., 2005). Although drought has been less prevalent in the last decade than the previous two, the underlying climate risk remains unchanged and could worsen with climate change (Robinson et al., 2013).

Second, poverty in Ethiopia has fallen considerably in the last decade as a result of successive years of good harvests and economic growth (World Bank 2015). This positive change has resulted in many individuals with per capita consumption now just above the national poverty line. These now non-poor individuals are likely still exposed to considerable risk, and could be vulnerable to falling back into poverty (Devarajan et al., 2013). However, it is possible that the growth experienced by Ethiopian households has made them both less poor and more resilient, and an empirical assessment is needed to determine the degree of vulnerability to poverty that is present in Ethiopia today.

Third, a large safety-net program was introduced between the two surveys used in the analysis, covering rural areas using geographical targeting. In 2005, the Government of Ethiopia introduced the Productive Safety Net Program (PSNP) in an attempt to transition food insecure households from an emergency food aid system to a more stable and predictable safety net. ${ }^{3}$ The program tackles chronic poverty, but also aims to protect beneficiaries and non-beneficiaries against drought. We can assess the impact of shocks on those covered by the program and comment on targeting. Finally, Ethiopia suffered from very high food price inflation during one of the survey years, providing insights to other low income countries with increasing urban populations that have been similarly affected by high food price inflation in recent years.

To preview our findings, we show that shocks do have a significant impact on the

\footnotetext{
${ }^{2}$ In Ethiopia, the largest administrative units are regions, then divided into 68 zones and 770 woredas.

${ }^{3}$ The program was designed and financed with the support of Development Partners.
} 
consumption of households in Ethiopia, with rainfall shortfalls and food price increases being the most important. A moderate drought reduces consumption by 9 percent for many rural households in drought prone areas and the rapid inflation witnessed in the first half of 2011 caused consumption losses up to 14 percent among many urban households. We find considerable heterogeneity of impacts, with uneducated households in urban areas suffering most from food price increases and those not covered by the safety net in rural areas suffering most from rainfall losses. ${ }^{4}$ When covered by the safety net, beneficiaries are better able to withstand shocks than non-beneficiaries, although this cannot be fully attributed to the presence of the program.

Vulnerability to poverty using our approach is 42 percent in rural areas, much higher than poverty (headcount just under 30 percent); vulnerability is 5 percentage points less prevalent than poverty in urban areas. This is on account of poverty having been measured in a year of good conditions in rural areas (good weather) and bad conditions in urban areas (high food price inflation). It highlights how a one-year snapshot of poverty such as afforded by a national consumption survey is not necessarily reflective of the relative vulnerability of different groups in the population, and also, that drought and inflation do not always coincide. Analyzing our various vulnerability measures by gender of the household head yields surprising results: female-headed households are more vulnerable in urban areas, the opposite is true in rural areas. PSNP targeting in rural areas appears to be good, but there are many households in rural woredas that are not covered by the program, and many vulnerable households in urban areas too.

The paper is structured as follows. Section 2 outlines the empirical method and data used to estimate the impact of weather and price shocks on household consumption. Section 3 discusses the literature on vulnerability measurement and how the estimated impact of weather and prices on consumption can be used to measure vulnerability to poverty. Section 4 presents results on the impact of weather and prices on consumption. Section 5 presents vulnerability estimates for 2011, with a breakdown by location and gender. Section 6 concludes with some policy recommendations.

\section{Quantifying the welfare impact of weather and price shocks}

\subsection{Method}

A particular focus of the methodology employed in this paper is in identifying an internally consistent estimate of the welfare losses caused by shocks.

The welfare measure used is that used by the Government of Ethiopia in estimating poverty, namely total expenditure on food and non-food consumption per adult equivalent (Woldehanna and Porter, 2013). The setting in which the household operates (the economic, legal and political environment) and the household's ability to cope with

\footnotetext{
${ }^{4}$ Households not covered by the safety net includes both beneficiary housheolds observed before the safety net was introduced and non-beneficiaries.
} 
shocks determines how shocks impact consumption such that consumption can be given by:

$$
\ln C_{h j k t}=X_{h j k t} \beta+S_{h j k t} \delta+S_{h j k t} * X_{h j k t}^{\prime} \gamma+\mu_{h}+\eta_{j}+\lambda_{k}+\psi_{t}+\epsilon_{h j k t}
$$

A household $h$ resides in community (woreda) $j$ within district (zone) $k$ at time $t$. Our explanatory variables are included in a vector $X$, comprising household and community characteristics; and $S$ is a vector comprising both idiosyncratic shocks (experienced by an individual household, or an individual within a household), and covariate or aggregate shocks (which affect a whole village, region, or possibly even the whole country). Time fixed effects, $\psi_{t}$, district fixed effects $\lambda_{k}$, woreda fixed effects $\eta_{j}$ and household fixed effects $\mu_{h}$ are unobserved.

Individuals for whom a shock $S$ has had a large negative impact are possibly more likely to report its occurrence than individuals who could mitigate the effects, thus calling into question the assumption of exogeneity when $S$ is measured using self-reported shocks. This is an assumption on which internally valid estimation of $\delta$ and $\gamma$ relies.

Using objective measures of shocks helps overcome this challenge. This is possible for covariate shocks such as weather and prices for which data on exposure is available. However, even with objective measures of shocks, the variation in the probability distribution of $S_{h j k t}$ cannot be considered exogenous to welfare across households.

We rely on the following observation to address this: although variation in the probability distribution of $S_{h j k t}$ may not be considered exogenous to welfare across households, the timing of a shock conditional on its distribution is exogenous (Thomas et al., 2010; Anttila-Hughes and Hsiang, 2013). Migration in Ethiopia is much lower than in other countries (see World Bank 2015), so bias from migration is quite unlikely. Controlling for the probability of occurrence and using objective measures of shocks improves the internal consistency of estimates of $\delta$ and $\gamma$ for drought and prices.

Variables that reflect the likelihood of a shock occurring, that can allay concern about the community unobserved effects, include dummies for agro-ecological zones of Ethiopia and moments of the location-specific historical distribution for covariate shocks are included in $X_{h j t}$. Some studies, e.g. Christiaensen and Subbarao (2005) construct a pseudo-panel of cohort or community-level data using two cross-section datasets which allows community fixed effects to be included. However, in our dataset, the communities chosen are not the same in both rounds, and also, our drought shock variable is at the community level which precludes the inclusion of community fixed effects, however we include a zone fixed-effect $\lambda_{k}$ to capture unobservable characteristics at this level as well as time fixed-effect $\psi_{t}$.

To also allow for non-linearities in the relationship between $X_{h j k t}$ and $l n C_{h j k t}$ we test the robustness of our findings on the impact of the most quantitatively important shock (drought) by using propensity score matching.

As the next section details, the years of data that are available for the analysis-2004 and 2010-are years in which rainfall shocks were observed, but not very large rainfall shocks (the last big rainfall shocks prior to the surveys were in 2002 and 2003). It is thus only possible to estimate the impact of moderate drought shocks. 
A rich set of household and community characteristics is included in $X_{h j k t}$ including education and sector of employment of the household head (plus highest education of males and females in the household), controls for demographics (household size and composition), assets and access to services, distance to the nearest market and road quality. This is done to ensure a good estimate of the non-stochastic element of household welfare is available for the vulnerability analysis. However with cross-sectional data as explicit in the equation above, there are still possibly some unobserved household characteristics, $\mu_{h}$, that are important for determining household welfare. This is therefore a caveat to the interpretation of our results.

\subsection{Data}

The base datasets for the analysis are the nationally representative Household Income Consumption Expenditure Survey (HICES) and Welfare Monitoring Surveys (WMS) of 2010/11 and 2004/05 (henceforth 2011 and 2005 respectively). These contain information on just over 20,000 households in each year. The HICES captures information on expenditure on food and other items. The WMS records household assets and characteristics as well as a fairly detailed module on self-reported adverse shocks. In both years they were administered by Ethiopia's Central Statistics Agency (CSA). The advantage of using the HICES-WMS for vulnerability analysis is that they are relatively large, nationally representative, comparable across years and allow measures of vulnerability to be estimated at the household level that can be related back to the official poverty measures calculated by the Government of Ethiopia (Woldehanna and Porter, 2013). This is extremely useful in a context where covariate shocks in particular (as our results show) can impact significantly on poverty numbers. The household level data allow us to look at the relative importance of geographic and household factors in determining vulnerability, and also how vulnerability varies across certain groups of households.

Data were collected on a rich set of self-reported idiosyncratic shocks experienced in the last 12 months. ${ }^{5}$ As discussed above, self-reported shocks are not always a good measure of exposure to a shock. However, for some clearly defined, salient events selfreporting can be expected to be more reliable. Job loss and death of household members are prevalent shocks that reflect clearly defined, salient events, and these are included in the analysis. There is also a self-reported food price shock where households are asked if they have been adversely affected by high consumer prices in the past year. This is used to test the robustness of the objective measure of food price shocks that we use.

For aggregate shocks, we use objective shock data reported outside the household survey and matched to households by location. The 2011 HICES was conducted from July 2010 to June 2011, with a random selection of households surveyed in each month. Starting in November of 2010, Ethiopia experienced a period of rapid food price inflation with inflation increasing substantially in a number of months, and particularly so in December. The consumption aggregate is converted to December 2010 prices for all

\footnotetext{
${ }^{5}$ Ten questions on shocks were asked in 2005 and twenty in 2011. However, for many of the categories fewer than 3 percent of households reported experiencing the shock, hence they are not included in our analysis.
} 
households using the CPI. Exploiting the variation in the timing of the survey we use the average rate of the monthly CPI increase in the three months prior to the survey interacted with a dummy for net-food consumers (defined as households in which nobody works in agriculture) to calculate the price shock experienced. ${ }^{6}$ Previous analysis has shown that there is a five month delay in the response of nominal wages to sudden food price increases (Headey et al., 2012).

In Ethiopia crop yields are very dependent on rainfall and vary considerably by year, and across regions. We take advantage of the fact that in Ethiopia, much analysis has been done by policymakers on variability of rainfall, and crop production. The Livelihoods, Early Assessment and Protection project (LEAP) system, developed in 2006 by the Government of Ethiopia in collaboration with the World Food Programme (Hoefsloot and Calmanti, 2012), uses crop-modeling approaches to estimate the likely rainfall-induced crop loss in woredas throughout Ethiopia based on a water balance model and crop types. ${ }^{7}$ The LEAP database contains estimates of the proportion of crop lost as a result of insufficient or poorly timed rainfall for each woreda from 1996 to 2012. These data are merged with the household survey data based on the woreda in which each household resides. ${ }^{8}$

Table 1 shows how frequently different shocks are reported in the data, with the most prevalent shocks being adverse food prices for urban areas, and drought and crop damage for rural areas. Food price shocks are reported far more in 2011. The proportion in 2005 reporting the shock was only $2 \%$, but almost $20 \%$ in 2011 , reflecting much higher monthly increases in the CPI present during the survey period in 2010/11. The crop loss figures from LEAP show the proportion of crops lost in each community, weighted by crop type (where zero means no crop losses suffered). In 2010, few if any households experienced crop losses of more than 30\%, whereas in 2005 there were some zones that experienced very high crop losses. In sum, 2011 was a better year for crops than 2005 (and better than a 15 year average) but a worse year for food price inflation (the worst in the last 15 years).

Table 2 shows the mean and standard deviations of the main variables used in the analysis.

\section{Estimating vulnerability to poverty}

\subsection{Measuring vulnerability}

Vulnerability to poverty is conceptually distinct from poverty, due to the uncertainty that is incorporated into the analysis (Moser, 1998; Alwang et al., 2001). The focus

\footnotetext{
${ }^{6}$ Note that this does correlate strongly with the self-reported price shock.

${ }^{7}$ See http://www.wfp.org/disaster-risk-reduction/leap, last accessed 28th October 2016. The LEAP model also provides corresponding estimates of the number of households in need of assistance based on a household economy model which can be seen as an alternative to our consumption based approach.

${ }^{8}$ Merging the two datasets together was a complex exercise, and approximately 8,000 observations were lost along the way mainly in pastoral areas.
} 
Table 1: Frequency of shocks

Proportion of households reporting shock:

\begin{tabular}{lcc} 
& 2005 & 2011 \\
\hline Food price & 0.02 & 0.19 \\
Drought & 0.10 & 0.05 \\
Crop damage & 0.09 & 0.03 \\
Job loss & 0.01 & 0.00 \\
\% Crop loss (from LEAP) & 23.49 & 13.82 \\
Average monthly increase in CPI & 0.2 & 1.7 \\
Times Woreda experienced over 50\% crop loss (past 15 years) & & 1.59 \\
\hline Notes: Shocks are self-reported, except for LEAP and CPI data. & &
\end{tabular}

in this paper is on vulnerability to absolute poverty, rather than to downturns in the wellbeing indicator (Kamanou and Morduch, 2002; Dutta et al., 2011) or vulnerability as welfare loss due to increased variance (Ligon and Schechter, 2003). We consider our method to be complementary to qualitative studies, or other approaches. We focus on the expected Foster Greer Thorbecke (FGT) measures that are the vulnerability analogues of the static poverty measures used in national policy, combining these with the CalvoDercon measure which is more sensitive to the threat of extreme poverty. Our focus is deprivation in the space of household consumption, suitably spatially deflated and adjusted for household composition. ${ }^{9}$

The first applied vulnerability measures that calculated expected poverty and probability of future poverty were developed around 15 years ago and are still most widely used (see Hoddinott and Quisumbing (2003) for a review). Empirically, household poverty is modeled as the realization of a stochastic process that generates consumption outcomes. If realized consumption falls below a poverty line $z$, the household is classified ex-post as a poor household. Vulnerability measurement, being ex-ante by definition, thus needs a poverty measure, a poverty line, and a prediction of future consumption based on assumptions about the stochastic process generating consumption. Household poverty is defined in the above papers using the FGT family of poverty indices (Foster et al., 1984): ${ }^{10}$

$$
P_{\alpha, h, t}=\left(\max \left\{0, \frac{z-c_{h t}}{z}\right\}\right)^{\alpha}
$$

With $\alpha=0$ being the headcount, 1 the poverty gap and 2 the squared gap. Chaudhuri et al. (2002) therefore defined vulnerability as the expectation (i.e. the predicted value) of poverty:

\footnotetext{
${ }^{9}$ Other perspectives have also been applied but are not used in this paper. For example, understanding the importance of assets for protecting livelihoods under stress, notably Moser (1998), and developed in economics through the work of Carter and Barrett (2006); Échevin (2013) and others. Dutta et al. (2011) and Günther and Maier (2014) consider that a desirable property for a vulnerability measure is to reference it to the starting point of household welfare.

${ }^{10}$ For convenience in this section we omit the community and district subscripts.
} 
Table 2: Summary statistics

\begin{tabular}{lcc}
\hline \multicolumn{1}{c}{ Variable } & Mean & Std. Dev. \\
\hline Household characteristics & & \\
Monthly consumption per adult (1996 Ethiopian birr) & 1757.374 & 2083.679 \\
Age of household head & 44.249 & 14.374 \\
Female headed household & 0.181 & 0.385 \\
Head primary education & 0.298 & 0.457 \\
Head secondary education & 0.051 & 0.22 \\
Head nonformal education & 0.044 & 0.206 \\
Household sector of occupation: agriculture & 0.352 & 0.261 \\
Household head unemployed & 0.003 & 0.057 \\
Household sector of occupation: manufacturing & 0.016 & 0.077 \\
Household sector of occupation: services or trade & 0.043 & 0.121 \\
Household size & 5.858 & 2.293 \\
Proportion of females 16-64 & 0.249 & 0.15 \\
Proportion of females under 15 & 0.242 & 0.179 \\
Proportion of females over 65 & 0.014 & 0.076 \\
Proportion of males under 15 & 0.249 & 0.184 \\
Proportion of males over 65 & 0.017 & 0.067 \\
Household dependency ratio & 0.513 & 0.204 \\
Household owns more than 3 plots & 0.531 & 0.499 \\
Household can raise 200 birr in a week & 0.755 & 0.43 \\
Household received income from PSNP in 2010 & 0.066 & 0.248 \\
Household net consumer of food & 0.481 & 0.5 \\
Household owns land & 0.913 & 0.283 \\
Household has own flush toilet/pit latrine & 0.388 & 0.487 \\
Household uses flush toilet/pit latrine & 0.5 & 0.5 \\
Household has corrugated iron roof & 0.382 & 0.486 \\
Household has electricity & 0.1 & 0.3 \\
Dummy: urban household that rents & 0.085 & 0.278 \\
Geographic characteristics & & \\
Rural Household & 0.849 & 0.358 \\
Ln Distance to market (km) & 3.726 & 1.229 \\
Close to market (less than median minutes) & 0.49 & 0.5 \\
Distance to town (minutes) & 288.226 & 201.758 \\
Shocks & 0.043 & 0.204 \\
Household suffered death of member & 0.007 & 0.086 \\
Household suffered job loss of member & 0.121 & 0.326 \\
Household suffered self-reported food price shock & 1.545 & 1.412 \\
Inflation rate (3-month moving average) & 14.848 & 18.928 \\
Drought: proportion lost crops & 37,964 \\
\hline & & \\
\hline
\end{tabular}

Notes: Descriptive statistics for 2005 and 2011 pooled. 


$$
V\left[P_{\alpha}, h, t\right]=E\left[\left(\max \left\{0, \frac{z-c_{h, t+1}}{z}\right\}\right)^{\alpha}\right]
$$

Pritchett et al. (2000) and Chaudhuri (2003) further extend the definition of vulnerability as a high probability that the future consumption falls below the poverty line:

$$
V_{h, t}=\operatorname{Pr}\left(c_{h, t+1} \leq z\right)
$$

In the binary measure, vulnerable households are defined as those with probability of consumption falling below the poverty line being greater than 0.5 . The advantage of this measure is that is very intuitive, and policy-relevant. However, it comes with the disadvantages that are associated with the headcount measure, that it is not sensitive to depth of poverty. Calvo and Dercon (2013) note particularly the concern that such vulnerability measures allow (even a small probability) good event to outweigh possible periods of deprivation. Ravallion (1988) and Kamanou and Morduch (2002) estimate the expected value of the squared poverty gap; in this case, poor households are implicitly assumed to have increasing absolute risk aversion.

Calvo and Dercon (2013) take an approach that they argue is a middle-ground between vulnerability as expected poverty and vulnerability as utility loss of increased risk. The authors propose a set of axioms extending those from static poverty measurement, that we summarize as focusing on the level of welfare in a particular realized state, and the probability of that state occurring, wherein if the probability of a lower welfare outcome increases, vulnerability should not fall. Their "No compensation" axiom incorporates the concept that for vulnerability purposes, an improvement in the best scenario should not compensate for bad (i.e. below the poverty line) scenarios. The authors offer a measure that depends on a constant relative risk sensitive (CRRS) measure, with risk sensitivity captured in a flexible parameter, $\theta$ :

$$
V_{h t}(z, p, c, t)=\frac{1}{\theta}\left(1-E\left[x_{h, t+1}^{\theta}\right]\right)
$$

Where $x_{h, t+1}=\tilde{c}_{h, t+1} / z$ and $\tilde{c}_{h, t+1}=c_{h, t+1}$ if $c_{h, t+1}<z$, and $\tilde{c}_{h, t+1}=z$ if $c_{h, t+1} \geq z$. This censored consumption is then expressed relative to the poverty line $z ; p$ are the set of probabilities for the realized states of consumption in the expectation term. ${ }^{11}$

\subsection{Estimating the probability distribution of future consumption}

Underpinning all of the above vulnerability measures is the empirical estimation of the cumulative density function (CDF) for future consumption $c_{h, t+1}$. We use the estimated impact of shocks on consumption and the estimated probability of their occurrence to generate the CDF of $c_{h, t+1}$ for each household.

\footnotetext{
${ }^{11}$ Note here that the Expected Poverty measures outlined in equation 3 above do also incorporate such censoring (e.g. the poverty gap is calculated, and then summed - therefore it is censored at the poverty line in each period).
} 
The earliest empirical work did not observe shocks, and relied on the cross-sectional distribution of consumption to impute the prospective distribution for each household. Chaudhuri (2003)) notes that the main drawback of this approach is that the method implicitly assumes that shocks to consumption experienced by different households are drawn from the same distribution. Later work modeled the variance of consumption as depending on household and community characteristics (Christiaensen and Subbarao, 2005), but did not adequately allow for the variance in consumption that results from covariate shocks such as weather or prices. Survey data necessarily only observe one (if cross-sectional) or a small number (if a panel) of weather and price outcomes. As a result relying only on the variation within survey data alone does not provide a complete estimate of the variation in consumption that arises from these shocks. As we show, this variation can be substantial and omitting this source of variation results in an underestimate of vulnerability.

For the idiosyncratic shocks of death and job loss, we assume that the cross-sectional distribution of the shock for a group of households with similar characteristics represents the probability distribution of this shock occurring in a future period. This is similar to other studies on vulnerability (Klasen et al., 2015). Household characteristics such as assets, schooling and gender of the household head, plus land, cattle, highland and pastoral in the rural areas are used to group households and estimate the probability of the shock occurring (given all of the idiosyncratic shocks were defined as binary events).

For drought shocks, the 17 year historic distribution of crop losses due to inadequate rainfall for each woreda using the LEAP dataset is used to define the distribution of future rainfall shocks. To our knowledge nobody has used the historic distribution of rainfall data to create future consumption distributions. For price shocks, the number of times large increases in the CPI have been observed since 2005 is used to calculate the probability that monthly inflation exceeds 1.5 percent on average in a given year. We do not assume any covariance in drought and price shocks for the following two reasons: (i) although there is a positive relationship between drought and price inflation in Ethiopia the two episodes of very high inflation observed since 2005 have been driven by high global food prices and monetary factors, not by poor rainfall, and (ii) drought is often local in Ethiopia and the best estimates available suggest that since 2004 crop losses have had limited local price effects.

These household-specific probability distributions are used to draw 6,000 sample realizations of each shock. The impact of the shock on consumption in each scenario is the realized shock drawn at random, multiplied by the impact of the shocks, $\delta$ and $\gamma$ as estimated from equation (5). We also incorporate a random error for each draw based on the empirical distribution of the regression residuals.

Although this method is appropriate for the type of shocks observed in the data, recall that the drought shock included in the regression analysis is a continuous measure, reflecting the proportion of normal crop yields lost due to insufficient rainfall, and that the two years of household survey data capture the moderate but not severe droughts experienced during the 17 years. Developing an accurate distribution of drought-induced consumption losses thus requires out-of-sample predictions on the magnitude of the loss.

For out-of-sample large drought shocks, we use other empirical evidence to guide the 
simulation exercise. Using the Ethiopia Rural Household Survey, Porter (2012) found that more extreme shocks impact consumption to a far greater extent than lesser shocks. Rainfall in the bottom quintile of the 30 year village distribution caused up to $20 \%$ drop in household consumption, whereas for the next quintile of the rainfall distribution (i.e. less than average rainfall, but to a lesser extent), the impact was around $2 \%$ (and nonsignificant). Therefore in the simulations we also allow crop-loss to have a non-linear impact on consumption, increasing ten-fold for shocks that are more than two standard deviations above the long-run mean.

The baseline consumption from the "fixed effects" or household and community characteristics is given by $X_{h j k t} \hat{\beta}$. Together, with the estimates of shock-induced consumption losses this allows us to calculate consumption for different states of the world for each household.

\subsection{Estimating vulnerability}

We create various vulnerability measures using the estimated CDF of $c_{h, t+1}$ for each household, noting that these capture vulnerability to the shocks that are captured in our data. ${ }^{12}$

We first define all those with a predicted consumption lower than the national poverty line as poor. The national absolute poverty numbers that are used by the Government of Ethiopia (Woldehanna and Porter, 2013) are based on the Foster-Greer-Thorbecke (FGT) family of poverty indices (Foster et al., 1984). A household is defined as poor if their total expenditure on all items is less than the national absolute poverty line of 3,781 birr in December 2010 prices. This is the amount of money needed to purchase food of 2,200 kilocalories for every adult-equivalent in the household, and other (extremely basic, necessary) items for everyone in the household.

We next define as "vulnerable", anyone with a probability of being poor higher than 0.5 across the 6,000 states of the world simulated (Pritchett et al., 2000; Chaudhuri, 2003). We also calculate the expected poverty gap and squared expected poverty gap (equation 3, with $\alpha=0,1,2$; Christiaensen and Subbarao (2005)) to show vulnerability to extreme poverty. Finally the Calvo-Dercon "no-compensation" vulnerability measure (Calvo and Dercon, 2013), with the $\theta$ risk exposure reaction parameter set to 2 , is also calculated. ${ }^{13}$

Finally, we note that we include only idiosyncratic shocks that negatively affect consumption, though a positive draw from the rainfall distribution would decrease poverty. To the extent that there are any other positive shocks experienced by households, our vulnerability estimates could be overestimates.

\footnotetext{
${ }^{12}$ Though noting that the HICES 2011 contained questions about 20 different shocks, including "other, specify" and there were no others with a frequency higher than 3 or 4 percent.

${ }^{13}$ In robustness checks, we vary the value of $\theta$ parameter.
} 


\section{Impact of weather and prices on consumption}

In this section we present results on the impact of weather and price shocks on consumption.

We estimate equation 1 pooling observations for 2005 and 2011, including zone and year fixed effects and allowing for clustering of the standard errors within zones. $X$ includes education (of the household head, as well as highest education level of the household), assets, indicators of employment, age, dependency ratio, disability, gender and woreda characteristics such as livelihood zone, access to market, probability of drought occurrence in the past, and urban/rural location (which proxies for exposure to price risk). A subset of $X$ is interacted with the shock variables. For drought $X$ includes dummies that capture whether a household lives in a drought prone area, cultivates a large or small amount of land, and, for those with little land, is a safety net beneficiary. As the safety net was introduced after the first survey, those that became beneficiaries after 2005 are not counted as beneficiaries in 2005. For price shocks, $X$ includes dummies that capture whether a household lives in urban areas, is educated and is female headed. Death and job-loss shocks are interacted with the same dummies. Table 3 shows the impact of shocks on consumption. In table 6 in the annex we show separately the results from the same model, for the "fixed" elements of households and communities.

Each increase in crop losses of 10 percent is correlated with a 3 percent fall in consumption for households not receiving the PSNP, cultivating few plots and living in drought-prone areas. The same 3 percent loss in consumption is also observed for households in drought prone areas that cultivate on a larger scale. Rainfall-induced crop losses have no significant impact on consumption for other households. Interestingly, land does not mitigate the impact of the drought, though the safety-net appears to (noting that drought was not so severe in 2011 when the PSNP was in operation). In a moderate drought crop-losses are about 30 percent suggesting that a moderate drought causes a drop in consumption of 9 percent for many households in drought prone areas.

To investigate the impact on poverty of an extreme weather shock we estimate the poverty rate were the weather conditions experienced in 2002-the worst drought recorded in the LEAP database-to be experienced again. In this simulation the headcount poverty rate would increase from $30 \%$ to $36 \%$, almost reversing all of the gains in poverty reduction recorded from 2005 to 2011.

Each 1 percentage point increase in the monthly inflation rate resulted in a 2 percent reduction in consumption for rural households, a 2.5 percent reduction for urban households with an educated household head and a 3.5-3.8 percent reduction in consumption for urban households with uneducated heads (female and male respectively). The impact of the food price shock in 2011 was therefore substantial, reducing consumption by 14 percentage points among households with uneducated heads given that the average monthly inflation was 3.87 percent from July 2010 to June 2011 (the start and end month of the survey). ${ }^{14}$

\footnotetext{
${ }^{14}$ In robustness checks we defines food price shock using the dummy self-report. The shock was associated with reduction in consumption by $10-13 \%$ for those affected in households with an uneducated female household head in an urban area. Educated households in urban areas, and rural households
} 
Table 3: Heterogeneous impact of shocks

\begin{tabular}{|c|c|}
\hline & $\begin{array}{c}(1) \\
\text { Ln consumption per adult (1996 prices) }\end{array}$ \\
\hline Death shock: rural hh many plots & $\begin{array}{l}-0.012 \\
(-0.63)\end{array}$ \\
\hline Death shock: rural hh few plots & $\begin{array}{l}0.018 \\
(0.64)\end{array}$ \\
\hline Death shock: urban hh head educated & $\begin{array}{c}-0.074^{* *} \\
(-2.73)\end{array}$ \\
\hline Death shock: urban hh head uneducated female & $\begin{array}{l}-0.064 \\
(-1.93)\end{array}$ \\
\hline Death shock: urban hh head uneducated male & $\begin{array}{l}-0.060 \\
(-1.25)\end{array}$ \\
\hline Job loss shock: rural hh & $\begin{array}{l}-0.066 \\
(-1.08)\end{array}$ \\
\hline Job loss shock: urban hh head educated & $\begin{array}{l}-0.044 \\
(-1.72)\end{array}$ \\
\hline Job loss shock: urban hh head uneducated female & $\begin{array}{l}0.038 \\
(0.57)\end{array}$ \\
\hline Job loss shock: urban hh head uneducated male & $\begin{array}{l}-0.042 \\
(-0.60)\end{array}$ \\
\hline Inflation: rural hh & $\begin{array}{c}-0.019^{* * *} \\
(-3.73)\end{array}$ \\
\hline Inflation: urban hh head educated & $\begin{array}{c}-0.025^{* * *} \\
(-5.47)\end{array}$ \\
\hline Inflation: urban hh head uneducated female & $\begin{array}{c}-0.035^{* * *} \\
(-5.60)\end{array}$ \\
\hline Inflation: urban hh head uneducated male & $\begin{array}{c}-0.038^{* * *} \\
(-5.03)\end{array}$ \\
\hline Drought: non drought prone community & $\begin{array}{c}-0.005^{* * *} \\
(-3.37)\end{array}$ \\
\hline Drought: drought prone, hh many plots & $\begin{array}{c}-0.003^{* * *} \\
(-5.69)\end{array}$ \\
\hline Drought: drought prone, hh few plots with PSNP & $\begin{array}{r}-0.002^{*} \\
(-2.55)\end{array}$ \\
\hline Drought: drought prone, hh few plots no PSNP & $\begin{array}{c}-0.003^{* * *} \\
(-6.03)\end{array}$ \\
\hline Adjusted R-sq & 0.43 \\
\hline Observations & 37969 \\
\hline
\end{tabular}


Death in the household has a large impact on consumption in urban areas (significant for households headed by uneducated females and by those with education) but no significant impact on consumption in rural areas. Job loss does not appear to have an impact on consumption, this may be due to the fact that relatively few people are in employment, and few report such a shock, resulting in low power to detect effects. We also re-estimated the model omitting the self-reported shocks of death and job loss given their potential bias. The results on the impact of rainfall and inflation were unchanged.

We performed several robustness checks on the estimated impact of rainfall-induced crop-loss (including a squared term on the shock and a nonlinear impact for shocks above $60 \%$ crop losses) and conclude that the results are fairly robust to our choice of specification. As an additional robustness check, we use propensity score matching methods ${ }^{15}$ to calculate the "treatment effect" of a higher than average drought. For this we created a dummy variable for the 'treatment' equal to one if the woreda experienced crop loss greater than the mean for the sample (13.6\% or higher), and matched households based on their characteristics and risk exposure. The ATT estimate was -.155 (s.e. =.0001). Given the distribution of the crop losses in the sample (32\% of households have experienced a drought shock defined in this way), the result is consistent with the marginal effect estimated in the regression model. We also estimated a within-zone pseudo panel model (i.e., collapsing to the average for each zone) and found similar, though less precise results for the price shock and the drought shock.

\section{$5 \quad$ Vulnerability estimates}

Using the methodology described in section 3 above, we calculated total vulnerability to poverty, as shown in table 4 . In 2011, vulnerability to poverty was $38.2 \%$, as measured by the proportion of the population that had a higher than $50 \%$ chance of falling below the poverty line (column 2). This shows that vulnerability is higher than poverty in Ethiopia (with a headcount rate of just under $30 \%$ as shown in column 1), as is often the case. Columns 3-5 outline some further measures of vulnerability that are more sensitive to depth of future poverty episodes (rather than simply the probability of falling below the line) as discussed in section 3. These are the expected poverty gap, expected squared poverty gap (both as outlined in equation 3 above). The final column shows the Calvo and Dercon (2013) "no compensation" measure (equation 5).

Although poverty is 4 percentage points higher in rural areas than urban areas, vulnerability according to all measures is substantially higher in rural areas. In particular, the measures that are sensitive to depth are more than twice as high in rural areas compared to urban areas, showing that it is rural households that are more vulnerable. Crop conditions were relatively good throughout Ethiopia in 2011. This may seem surprising given this was the onset of the Horn of Africa drought, but the crisis largely affected the pastoral regions of the country, which are not included in our sample. The relatively good crop conditions in non-pastoral regions resulted in lower levels of poverty for many

were not impacted by the shock so defined (see Table 7 in the annex).

15 teffects psmatch in stata 13. 
Table 4: Vulnerability Estimates, 2011

\begin{tabular}{lccccc}
\hline \hline & Headcount & $\mathrm{V}$ (prob) & $\mathrm{E}$ (Pov Gap) & $\mathrm{E}$ (Squared Gap) & Calvo-Dercon \\
\hline All & 0.294 & 0.382 & 0.082 & 0.050 & 0.142 \\
Standard error) & & $(0.003)$ & $(0.001)$ & $(0.001)$ & $(0.001)$ \\
& & & & & \\
\hline Urban Households & 0.261 & 0.210 & 0.038 & 0.020 & 0.065 \\
(Standard error) & & $(0.003)$ & $(0.001)$ & $(0.000)$ & $(0.001)$ \\
Rural Households & 0.302 & 0.416 & 0.082 & 0.050 & 0.142 \\
(Standard error) & & $(0.005)$ & $(0.001)$ & $(0.001)$ & $(0.002)$ \\
\hline \hline
\end{tabular}

Notes: Survey-weighted proportion of population that have the characteristics. Headcount is the Foster et al. (1984) headcount measure, E(pov gap) and E(squared gap) are the expected values of the FGT poverty measures respectively. The final column is Calvo and Dercon (2013) measure with parameter $\theta$ set at one-third. Bootstrapped standard errors in brackets.

households as higher crop incomes allowed them to consume more. Although households were less poor in 2011 than in previous years, they were still quite vulnerable to poverty in the future. In urban areas more households were poor in 2011 (26 percent) than had a higher than 50 percent chance of being poor in the future (21 percent). This reflects the fact that urban household were experiencing a very bad year in 2011 as a result of high price inflation.

We explore next whether there are gender differences in the urban and rural vulnerability profiles. Klasen et al. (2015) examine the correlates of poverty and vulnerability in Thailand and Vietnam with respect to gender of the household head, and find that in both countries, female headed households are more vulnerable, though this is driven by different factors: higher exposure to shocks in Thailand, and higher poverty in Vietnam. The authors also call for more gender disaggregated poverty and vulnerability analysis as a guide to policy. In Ethiopia there are still significant gaps between male and female adult outcomes, especially with regard to education and literacy - in 2011, more than half of Ethiopian women had no education (compared with 38 percent of men). We therefore calculated our various vulnerability measures, disaggregated by gender, for both urban and rural areas. Table 7 in the annex shows some key descriptive statistics disaggregated by location and gender. The results show that in rural areas female-headed households have significantly lower levels of vulnerability (37 percent) than male-headed households (42 percent). This result is fairly consistent across all of our calculated vulnerability measures. In contrast, female-headed households show significantly higher vulnerability in urban areas, with 22 percent being likely to be poor, compared to 20 percent of male-headed households. Referring back to our regression results in table 3, we found that uneducated households suffered most from food price shocks. Higher urban vulnerability can in part be attributed to the fact that female headed households have lower levels of education. For the rural results, we see that female headed households have slightly lower poverty than male headed households. We also find that the impact of drought was lower for PSNP beneficiaries with low land holdings (which describes most female-headed households), and so PSNP targeting of female headed households could 
explain the difference.

Table 5: Vulnerability by gender of household head, 2011

\begin{tabular}{|c|c|c|c|c|c|}
\hline & "Headcount & $\overline{\mathrm{V} \text { (prob) }}$ & $\overline{\mathrm{E} \text { (Pov Gap) }}$ & E(Squared Gap) & Calvo-Dercon \\
\hline \multicolumn{6}{|l|}{ Rural Households } \\
\hline Male-head & 0.307 & 0.424 & 0.092 & 0.057 & 0.159 \\
\hline (Standard error) & & $(0.006)$ & $(0.002)$ & $(0.001)$ & $(0.003)$ \\
\hline Female-head & 0.274 & 0.372 & 0.084 & 0.054 & 0.147 \\
\hline (Standard error) & & $(0.011)$ & $(0.003)$ & $(0.002)$ & $(0.005)$ \\
\hline \multicolumn{6}{|l|}{ Urban Households } \\
\hline Male-head & 0.243 & 0.204 & 0.038 & 0.020 & 0.064 \\
\hline (Standard error) & & $(0.004)$ & $(0.001)$ & $(0.001)$ & $(0.002)$ \\
\hline Female-head & 0.282 & 0.225 & 0.039 & 0.020 & 0.067 \\
\hline (Standard error) & & $(0.006)$ & $(0.001)$ & $(0.001)$ & $(0.002)$ \\
\hline
\end{tabular}

Notes: Survey-weighted proportion of population that have the characteristics. Other notes as in table 4 above.

Unreliable rainfall has historically underpinned much of the discussion on vulnerability in Ethiopia given the predominance of livelihoods that are dependent on rainfed production systems. This characterization of vulnerability has resulted in a widespread understanding of a geographic footprint of vulnerability, with more drought prone places characterized as more vulnerable. Safety net interventions have been targeted in these areas. We compared the level of vulnerability across geographic types (according to altitude and crop reliability). We find that vulnerability still has a strong geographic footprint in Ethiopia. The moisture reliable lowlands are the most vulnerable places in Ethiopia in 2011, followed by the Enset-growing lowlands and the drought-prone highlands. It may at first seem surprising that the moisture reliable lowlands are the most vulnerable places in Ethiopia, given that by their definition moisture is indeed more reliable in these areas. However, poverty, although falling, is still very high in the moisture reliable lowlands. More than half, 59\%, of residents were poor in 2005. This fell substantially to $45 \%$ in 2011 , though was still 13 percentage points higher than the next geographic area. Vulnerability is high in these lowlands not because residents are more subject to climate shocks that will drive them into poverty, but because residents are already poor. Lower levels of education and asset ownership result in our model predicting higher vulnerability in these areas.

However, even though vulnerability may have a geographic footprint in Ethiopia, much vulnerability is not geographically determined, but instead determined by other factors such as individual access to assets, or lifecycle events. This causes individuals everywhere, in every woreda of Ethiopia, to be vulnerable. We compared the proportion of vulnerable households in PSNP and non-PSNP woredas. Our results show that the PSNP is targeted to many of the most vulnerable areas: in particular, the vulnerable enset lowlands and to the drought prone highlands. However they also point to a need for safety nets in the moisture reliable lowlands, and at present very few woredas in these areas are included in the PSNP. Indeed, a safety net program that is targeted to 
specific woredas will necessarily result in many vulnerable Ethiopians being left without protection. The analysis finds that 37 percent of households living in non-PSNP woredas are vulnerable to absolute poverty.

\section{Conclusions and policy implications}

We use a nationally representative dataset merged with climate and price data to estimate the impact of climate and price shocks on household consumption. We find that many Ethiopians are unable to protect their consumption against lack of rainfall and sudden increases in food prices. There is considerable heterogeneity in the impact of all types of shocks. Rural households in drought prone areas that are not currently recipients of the safety net, and households with little education in urban areas are most at risk to suffer drops in their consumption. We estimate that a moderate drought causes a 9 percent reduction in consumption for households that are not covered by the PSNP in drought-prone areas. This implies a substantial increase in poverty when rains are poor. As an example, were the drought of 2002 to be repeated, we estimate that the headcount poverty rate would increase by 21 percentage points from 30 to 51 percent. Sudden food price increases can be similarly devastating for urban households. We estimate that the high inflation experienced in the first half of 2011 resulted in a reduction of 14 percent in the consumption of uneducated households in urban areas.

We take actual distributions of climate and price shocks in each district to simulate the probable ex-ante distribution of consumption and use this to quantify vulnerability to poverty in Ethiopia. Our numbers can be compared directly to official poverty numbers, to show how sensitive current poverty estimates are to shocks that are prevalent in the context. We find that 42 percent of rural households are vulnerable to poverty, but only 21 percent of urban households. Vulnerability to poverty is much higher than poverty in rural areas but this is not the case in urban areas, reflecting the fact that the household survey was conducted during a year of good conditions for rural households and very difficult conditions for urban households. Within rural areas, vulnerability is higher in areas prone to drought. However, much vulnerability is not geographically determined, but instead determined by other factors such related to gender and education. We show that the ranking of vulnerability across groups (e.g. rural female, rural male) are fairly stable across the choice of measure, though measures that are more sensitive to depth of potential deprivation should also be carefully checked.

The methodology used avoids a number of the limitations of cross-section data where possible but caveats to the analysis remain with regard to unobserved household characteristics. For this type of analysis, the data requirements are indeed high, and future challenges include generalizing estimates of consumption more reliably out-of-sample in order to improve the vulnerability estimates (Anttila-Hughes and Sharma, 2014).

In terms of policy, the results highlight the need for caution in using poverty data collected once every five years to target programs, as underlying rates of vulnerability can be quite different from the poverty rate captured at one point in time. More frequent

collection of poverty data, and vulnerability analysis such as performed in this paper can 
help address this concern.

The results also point to the need to protect households from large covariate shocks, particularly households for whom shocks are most costly. Safety nets can help households manage agricultural risk such as drought, but other risk management instruments can also help, particularly for households that are better-off and unlikely to be included in safety net programs. Agricultural index insurance has been piloted in a number of sites in Ethiopia, and research suggests that if offered through the right institutional set-up, and with some subsidization of marketing costs, it will be purchased by a number of farmers (Berhane et al., 2012; Dercon et al., 2014). The World Food Programme and Oxfam have also piloted incorporating index insurance with the PSNP. This has resulted in high demand for insurance among PSNP households. Further work is also ongoing on using indexes to trigger payments from a risk pool (such as in the African Risk Capacity ${ }^{16}$ ) at a national level in order to support increased safety net disbursements during times of widespread drought.

A number of options may be available to increase protection for rural households against bad weather, but this analysis has also shown that households-particularly urban households-need protection from food price shocks also. The high impact of food price shocks in urban areas points to the need for urban safety nets that are able to respond to sudden price increases. Further research on what causes slow nominal wage adjustment in urban areas, such as fixed nominal wages in the public sector (World Bank, 2016), may shed light on additional policy interventions that can reduce the impact of this risk on urban welfare.

\footnotetext{
${ }^{16}$ A special agency of the African Union, also funded by development partners. http://www. africanriskcapacity.org/ last accessed 26th January 2015.
} 


\section{References}

Alem, Y. and Söderbom, M. (2012). Household-level consumption in urban ethiopia: The effects of a large food price shock. World Development, 40(1):146-162.

Alwang, J., Siegel, P. B., and Jorgensen, S. L. (2001). Vulnerability: a view from different disciplines. Technical report, Social protection discussion paper series.

Anttila-Hughes, J. and Sharma, M. (2014). Linking risk models to microeconomic indicators. Microeconomics and Catastrophe Risk Modelling Paper 2, World Bank.

Anttila-Hughes, J. K. and Hsiang, S. M. (2013). Destruction, disinvestment, and death: Economic and human losses following environmental disaster. Available at SSRN 2220501.

Berhane, G., Clarke, D., Dercon, S., Hill, R. V., and Taffesse, A. S. (2012). Financial innovations for social and climate resilience: Ethiopia case study. Research report.

Calvo, C. and Dercon, S. (2013). Vulnerability to individual and aggregate poverty. Social Choice and Welfare, 41(4):721-740.

Carter, M. R. and Barrett, C. B. (2006). The economics of poverty traps and persistent poverty: An asset-based approach. The Journal of Development Studies, 42(2):178199.

Chaudhuri, S. (2003). Assessing vulnerability to poverty: concepts, empirical methods and illustrative examples. Department of Economics Columbia University available at: http://info. worldbank. org/etools/docs/library/97185/Keny_0304/Ke_0304/vulnerabilityassessment. pdf.

Chaudhuri, S., Jalan, J., and Suryahadi, A. (2002). Assessing household vulnerability to poverty from cross-sectional data: A methodology and estimates from indonesia. Working paper, Department of Economics, Columbia University.

Christiaensen, L. J. and Subbarao, K. (2005). Towards an understanding of household vulnerability in rural kenya. Journal of African Economies, 14(4):520-558.

Dell, M., Jones, B. F., and Olken, B. A. (2014). What do we learn from the weather? the new climate-economy literature. Journal of Economic Literature, 52(3):740-98.

Dercon, S. (2004). Growth and shocks: evidence from rural ethiopia. Journal of Development Economics, 74(2):309-329.

Dercon, S., Hill, R. V., Clarke, D., Outes-Leon, I., and Seyoum Taffesse, A. (2014). Offering rainfall insurance to informal insurance groups: evidence from a field experiment in ethiopia. Journal of Development Economics, 106:132-143.

Dercon, S., Hoddinott, J., and Woldehanna, T. (2005). Shocks and consumption in 15 ethiopian villages, 1999-2004. Journal of African economies. 
Dercon, S. and Krishnan, P. (2000). Vulnerability, seasonality and poverty in ethiopia. Journal of Development Studies, 36(6):25.

Devarajan, S., Go, D. S., Maliszewska, M., Osorio-Rodarte, I., and Timmer, H. (2013). Stress-testing africa's recent growth and poverty performance. Technical report, The World Bank.

Dutta, I., Foster, J., and Mishra, A. (2011). On measuring vulnerability to poverty. Social Choice and Welfare, 37(4):743-761.

Échevin, D. (2013). Measuring vulnerability to asset-poverty in sub-saharan africa. World Development, 46:211-222.

Foster, J., Greer, J., and Thorbecke, E. (1984). A class of decomposable poverty measures. Econometrica: Journal of the Econometric Society, pages 761-766.

Günther, I. and Maier, J. K. (2014). Poverty, vulnerability, and reference-dependent utility. Review of Income and Wealth, 60(1):155-181.

Headey, D., Nisrane, F. B., Worku, I., Dereje, M., and Taffesse, A. S. (2012). Urban wage behavior and food price inflation: The case of ethiopia. Ethiopia Strategy Support Programme II Working Paper, 41.

Hoddinott, J. and Quisumbing, A. R. (2003). Methods for microeconometric risk and vulnerability assessments. Technical report, The World Bank.

Hoefsloot, P. and Calmanti, S. (2012). Leap version 2.61 for ethiopia user manual. Technical report, The World Bank.

Kamanou, G. and Morduch, J. (2002). Measuring vulnerability to poverty, volume 58. WIDER Discussion Papers-World Institute for Development Economics (UNU-WIDER).

Klasen, S., Lechtenfeld, T., and Povel, F. (2015). A feminization of vulnerability? female headship, poverty, and vulnerability in thailand and vietnam. World Development, $71: 36-53$.

Ligon, E. and Schechter, L. (2003). Measuring vulnerability*. The Economic Journal, 113(486):C95-C102.

Moser, C. O. (1998). The asset vulnerability framework: reassessing urban poverty reduction strategies. World development, 26(1):1-19.

Porter, C. (2012). Shocks, consumption and income diversification in rural ethiopia. Journal of Development Studies, 48(9):1209-1222.

Pritchett, L., Suryahadi, A., and Sumarto, S. (2000). Quantifying vulnerability to poverty: A proposed measure, applied to indonesia. Technical Report 2437, World Bank. 
Ravallion, M. (1988). Expected poverty under risk-induced welfare variability. The Economic Journal, pages 1171-1182.

Robinson, S., Strzepek, K., and Cervigni, R. (2013). The cost of adapting to climate change in ethiopia: Sector-wise and macro-economic estimates. Ethiopia Strategy Support Program II (ESSP) working Paper, 53.

Thomas, T., Christiaensen, L., Do, Q.-T., and Trung, L. D. (2010). Natural disasters and household welfare: evidence from vietnam. World Bank Policy Research Working Paper Series.

Woldehanna, T. and Porter, C. (2013). Poverty and growth in ethiopia (1995/96 2010/11): The poverty reduction legacy of meles zenawi and future challenges. Technical report, Government of Ethiopia.

World Bank (2014). World development report 2014: Risk and opportunity. Technical report, World Bank.

World Bank (2016). Why so idle? wages and employment in a crowded labor market. fifth ethiopia economic update. Technical report, World Bank. 
Annex: Additional Tables 


\section{Table 6: Household Characteristics}

\begin{tabular}{|c|c|}
\hline Dummy: female uneducated Household head & $\begin{array}{c} \\
\text { Ln consumption per adult (1996 prices) } \\
-0.004 \\
(-0.14)\end{array}$ \\
\hline Dummy: male uneducated Household head & $\begin{array}{l}-0.004 \\
(-0.15)\end{array}$ \\
\hline Rural Household & $\begin{array}{l}0.044 \\
(0.38)\end{array}$ \\
\hline Age of household head & $\begin{array}{c}-0.004^{* * *} \\
(-15.11)\end{array}$ \\
\hline Female headed Household & $\begin{array}{c}-0.063^{* * *} \\
(-6.05)\end{array}$ \\
\hline Head primary edu & $\begin{array}{l}0.039 \\
(1.33)\end{array}$ \\
\hline Head completed secondary education & $\begin{array}{c}0.197^{* * *} \\
(6.23)\end{array}$ \\
\hline Head nonformal edu & $\begin{array}{l}0.062 \\
(1.95)\end{array}$ \\
\hline Drought prone village & $\begin{array}{c}0.094^{* * *} \\
(3.47)\end{array}$ \\
\hline Logarithm of household size & $\begin{array}{c}-0.511^{* * * *} \\
(-23.88)\end{array}$ \\
\hline Proportion of females $16-64$ & $\begin{array}{c}0.261^{* * *} \\
(7.13)\end{array}$ \\
\hline Proportion of females under 15 & $\begin{array}{c}0.206^{* * *} \\
(6.97)\end{array}$ \\
\hline Proportion of females over 65 & $\begin{array}{c}0.420^{* * *} \\
(5.86)\end{array}$ \\
\hline Proportion of males under 15 & $\begin{array}{c}0.177^{* * *} \\
(5.83)\end{array}$ \\
\hline Proportion of males over 65 & $\begin{array}{c}0.267^{* * *} \\
(3.45)\end{array}$ \\
\hline Ln Distance to market & $\begin{array}{l}0.004 \\
(0.56)\end{array}$ \\
\hline Close to market (less than median minutes) & $\begin{array}{l}-0.016 \\
(-1.09)\end{array}$ \\
\hline Household owns land & $\begin{array}{c}-0.029^{*} \\
(-2.24)\end{array}$ \\
\hline Household owns more than 3 plots & $\begin{array}{c}0.056^{* * *} \\
(5.89)\end{array}$ \\
\hline Household has corrugated iron roof & $\begin{array}{c}0.107^{* * *} \\
(10.88)\end{array}$ \\
\hline Household uses flush toilet/pit latrine & $\begin{array}{c}0.060^{* * *} \\
(5.64)\end{array}$ \\
\hline Household has own flush toilet/pit latrine & $\begin{array}{c}0.054^{* * *} \\
(6.29)\end{array}$ \\
\hline Household has electricity & $\begin{array}{c}-0.037^{*} \\
(-2.30)\end{array}$ \\
\hline Dummy: urban household that rents & $\begin{array}{c}0.125^{* * *} \\
(9.64)\end{array}$ \\
\hline Observations & 37969 \\
\hline
\end{tabular}


Table 7: Descriptive statistics: Urban and Rural, male and female households

\begin{tabular}{lcccccc}
\hline & Expenditure & Death shock & Job loss & Food price & Crop loss & PSNP \\
\hline Urban male & 3131.669 & 0.01 & 0.012 & 0.185 & 0 & 0.023 \\
Urban Female & 3041.826 & 0.022 & 0.013 & 0.208 & 0 & 0.053 \\
Rural male & 1661.1 & 0.008 & 0.001 & 0.184 & 11.729 & 0.116 \\
Rural female & 1735.116 & 0.04 & 0.002 & 0.217 & 12.884 & 0.185 \\
\hline
\end{tabular}

Notes: Variables defined in Table 2. 
Table 8: Self-reported food-price shocks

\begin{tabular}{|c|c|}
\hline & $\begin{array}{c}(1) \\
\text { Ln consumption per adult (1996 prices) }\end{array}$ \\
\hline Death shock: rural hh many plots & $\begin{array}{l}-0.014 \\
(-0.74)\end{array}$ \\
\hline Death shock: rural hh few plots & $\begin{array}{l}0.028 \\
(0.99)\end{array}$ \\
\hline Death shock: urban hh head educated & $\begin{array}{c}-0.070^{* *} \\
(-2.66)\end{array}$ \\
\hline Death shock: urban hh head uneducated female & $\begin{array}{l}-0.040 \\
(-1.19)\end{array}$ \\
\hline Death shock: urban hh head uneducated male & $\begin{array}{l}-0.047 \\
(-1.03)\end{array}$ \\
\hline Job loss shock: rural hh & $\begin{array}{l}-0.044 \\
(-0.75)\end{array}$ \\
\hline Job loss shock: urban hh head educated & $\begin{array}{l}-0.036 \\
(-1.44)\end{array}$ \\
\hline Job loss shock: urban hh head uneducated female & $\begin{array}{l}0.041 \\
(0.61)\end{array}$ \\
\hline Job loss shock: urban hh head uneducated male & $\begin{array}{l}-0.006 \\
(-0.10)\end{array}$ \\
\hline Food price shock: rural hh & $\begin{array}{l}-0.008 \\
(-0.47)\end{array}$ \\
\hline Food price shock: urban hh head educated & $\begin{array}{l}-0.018 \\
(-1.05)\end{array}$ \\
\hline Food price shock: urban hh head uneducated female & $\begin{array}{c}-0.077^{* *} \\
(-2.74)\end{array}$ \\
\hline Food price shock: urban hh head uneducated male & $\begin{array}{l}-0.042 \\
(-1.25)\end{array}$ \\
\hline Drought: non drought prone community & $\begin{array}{c}-0.005^{* * *} \\
(-3.43)\end{array}$ \\
\hline Drought: drought prone, hh many plots & $\begin{array}{c}-0.003^{* * *} \\
(-5.69)\end{array}$ \\
\hline Drought: drought prone, hh few plots with PSNP & $\begin{array}{l}-0.002 \\
(-1.82)\end{array}$ \\
\hline Drought: drought prone, hh few plots no PSNP & $\begin{array}{c}-0.003^{* * *} \\
(-6.43)\end{array}$ \\
\hline $\begin{array}{l}\text { Adjusted R-sq } \\
\text { Observations }\end{array}$ & $\begin{array}{c}0.45 \\
39577\end{array}$ \\
\hline
\end{tabular}

$t$ statistics in parentheses

${ }^{*} p<0.05,{ }^{* *} p<0.01,{ }^{* * *} p<0.001$

Notes: This table replicates results in table 3, but the food price shock is self-reported rather than CPI. Controls as those of table 3 . Robust $t$ statistics in parentheses. 